\title{
Modeling Direct Ethylene Hydration over Zirconium Tungsten Catalyst: Fundamental of Ethanol Production Using the Biggest Global Ethylene Feeding Pipeline in Iran
}

\author{
Behrooz Roozbehani ${ }^{1}$, Saeedeh Imani Moqadam ${ }^{2}$, Mojtaba Mirdrikvand ${ }^{2} \&$ Ali Cheshmeh Roshan ${ }^{2}$ \\ ${ }^{1}$ Head of Research Center of Petroleum University of Technology, Abadan Faculty of Chemical Engineering, \\ Abadan, Iran \\ 2 Researcher in Research Center of Petroleum University of Technology, Abadan Faculty of Chemical \\ Engineering, Abadan, Iran \\ Correspondence: Mojtaba Mirdrikvand, Research Center of Petroleum University of Technology, Abadan \\ Faculty of Chemical Engineering, North Bowarde, Abadan 63165, Iran. Tel: 98-939-174-4889. E-mail: \\ mirdrikvand@gmail.com
}

Received: May 14, 2012 Accepted: June 20, 2012 Online Published: August 15, 2012

doi:10.5539/eer.v2n2p28 URL: http://dx.doi.org/10.5539/eer.v2n2p28

\begin{abstract}
Ethanol is produced through two methods of fermenting and hydration of ethylene. In this article, regarding low rates of ethanol production in Iran $\left(1.5 \times 10^{8}\right.$ liters per year) and extreme requirement of global industry to ethanol as a fuel additive, the capacity of ethanol production in Iran has been discussed. Adding ethanol to fuels would make them environmental friendly and as a result, huge amounts of ethanol would be required. It is declared that Iran, having the biggest ethylene pipeline in the world, has the potential of massive ethanol production and could play a pivotal role for global ethanol manufacturing in the near future. In addition, producing ethanol and exporting it is investigated via the simulation of an ethanol factory. Direct hydration of ethylene is the recommended method in this study. Simulation of this process was done using HYSYS software and the optimization results are illustrated based on Aspen Plus software.
\end{abstract}

Keywords: aspen plus, HYSYS, ethylene, Iran, optimization

\section{Introduction:}

Ethanol as one of the most well-known oxygen-containing organic materials has a wide variety of applications. Ethanol in medical applications such as sterilization of medical instruments, dressings, directly in the formulation of some drugs and non-medical costs, as additives to fuel motor vehicles, production of vinegar, a variety of solvents, paints and other fields of application are numerous(Renewable Fuels Association, 2012).

Official statistics illustrate that global produced ethanol was around $1.02 \times 10^{11}$ liters in year 2010 (Ethanol Industry News, 2011). Most ethanol (approximately 93 percent) in the world is produced through fermentation and only about 7 percent is made synthetically (Nelson, 1951; Maki et al, 1998). The principal suppliers of synthetic ethanol are multi-national companies' plants like Sasol companies in Europe and South Africa, Equistar Company in the United States and SADAF Company in Saudi Arabia (Ethanol Industry News, 2011). The initial stages and materials vary based on production methods of ethanol. Moreover, the biggest synthetic ethanol manufacturing plants are in Germany and Scotland with a production rate of $1.7 \times 10^{8}$ liters per year (Gilmartin, 2005; Bristow, 2011).

It has been declared that ethanol production through fermentation is much too volatile to allow for a secure and constant supply of ethanol in the region (Chemical Industry News \& Intelligence, 1998). On the other hand, it is said that synthetic production of ethanol seems to be less economical in the U.S. which is due to high costs of ethylene, the initial materials of the Regarding the existence of many incomplete and unoptimized technologies for the production of reaction, and the great features of their farming products that allow them use fermenting methods for agricultural wastes (Chemical Industry News \& Intelligence, 1998, 2005). Figure 1 shows the main global exports of ethanol in 2005 (FO Licht, 2006). 


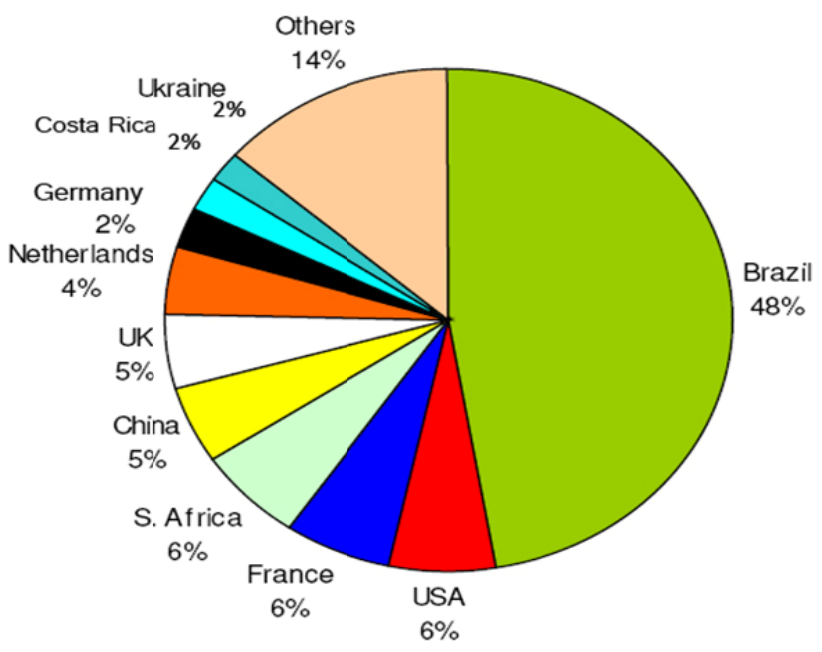

Figure 1. Main export portion of ethanol in 2005 (FO Licht, 2006)

Economic estimation of ethanol production conditions differs based on geographical locations; In the U.S. for instance, synthetic method of ethanol production tends to decrease while in a country like Saudi Arabia, having similar features to Iran and other Middle East countries, it is considerably increasing (Logsdon, 1994; SADAF, 2010). In the region of Middle East, countries like Saudi Arabia and Qatar are using this production method in some companies; however, it has not yet been widely used and spread (Gilmartin, 2005; Logsdon, 1994).

In Iran, over 100 million liters of ethanol are produced accordingly in 30 companies. It is worth noting that Iran's quota in global production of ethanol is about 0.05 percent (Ethanol News Magazine, 2010). In Iran, decrease of agricultural molasses products, founding the biggest world ethylene pipelines and therefore the accessible low cost ethylene, conceives the idea that synthetic ethanol production is the best way of an optimized condition (Ethanol News Magazine, 2009). Iran has a great advantage in producing ethylene, propylene and their derivatives due to its abundant, cheap and convenient sources. The West Ethylene Pipeline is the biggest ethylene pipeline which transfers produced ethylene in Asalouyeh region to the west of Iran. This region is one of the world's largest exporters of petrochemicals targeting markets in Europe and Asia.

The West Ethylene Pipeline was initially launched for $1500 \mathrm{Km}$ with the capacity of $1.2 \times 10^{12}$ Liter to feed five designed petrochemical complexes. As the number of those complexes increased, the pipeline's length was increased to $2100 \mathrm{Km}$ with the capacity of $2.2 \times 10^{12}$ Liter. Construction of the pipeline started in 2003 and it will supply needed feedstock to petrochemical companies which are to be built in Gachsaran, Khorramabad, Kermanshah, Sanandaj, Mahabad, Hamedan, Myandoab, Dehdasht, Andimeshk, and Chaharmahal-Bakhtiari regions in Iran. Consequently, implementing this enhanced design of a synthetic ethanol production factory for producing fuel additive is available not only for the Middle East but also for the entire world is speculated. The location of West Pipeline is shown in the Figure 2 (NPC News Bulletein, 2005). This ethanol can be made with high purity through a careful calculation and modelling.

In the current decade, due to focusing on environmental concerns and environmental friendly technologies, bioethanol has become a valuable and strong option in the global energy market as an additive for vehicles. Consequently, the development of cost-effective technologies for fuel ethanol production has been a priority for many researchers and also governments. Ethanol process engineering tools and functions are highly required. Process engineering applied to the production of fuel ethanol includes the design of new innovative process configurations which implies reducing fuel ethanol production costs. After all, design process of synthesis, makes a good opportunity for the formulation of finding the most improved techno-economical and environmental industry (Carlos \& Oscar, 2007). As a result, process optimization is another vital element that must be utilized in the framework of the process. Optimization plays a key role not only during the experiment, but also through the design steps.

This study is conducted to investigate the basic elements required to improve -and better saying commencesynthetic ethanol production in Iran. In addition, the catalytic hydration using Zirconium Tungsten catalyst is thoroughly elaborated using HYSYS 3.2 software for simulating the process. Eventually, optimization of the process is done through ASPEN PLUS 11.1 Software and the benefits are discussed in detail. 


\section{Process Simulation of the Synthetic Plant with $87 \%$ Purity}

Direct hydration of ethylene has been invented about 50 years ago in chemical industry over catalysts consisting of diatomaceous earth or silica gel, impregnated with loadings of orthophosphoric acid (Millidge, 1969). In brief, ethanol synthesis process includes three steps: reacting, recycling, and purifying (Sommer \& Bücker, 1983; Devon, 1972). We simulated the process using NRTL FLUID PACKAGE model with HYSYS 3.2 software looking for the efficiency of reaction progress in the reactor. Figure 2 shows the results of this simulation.

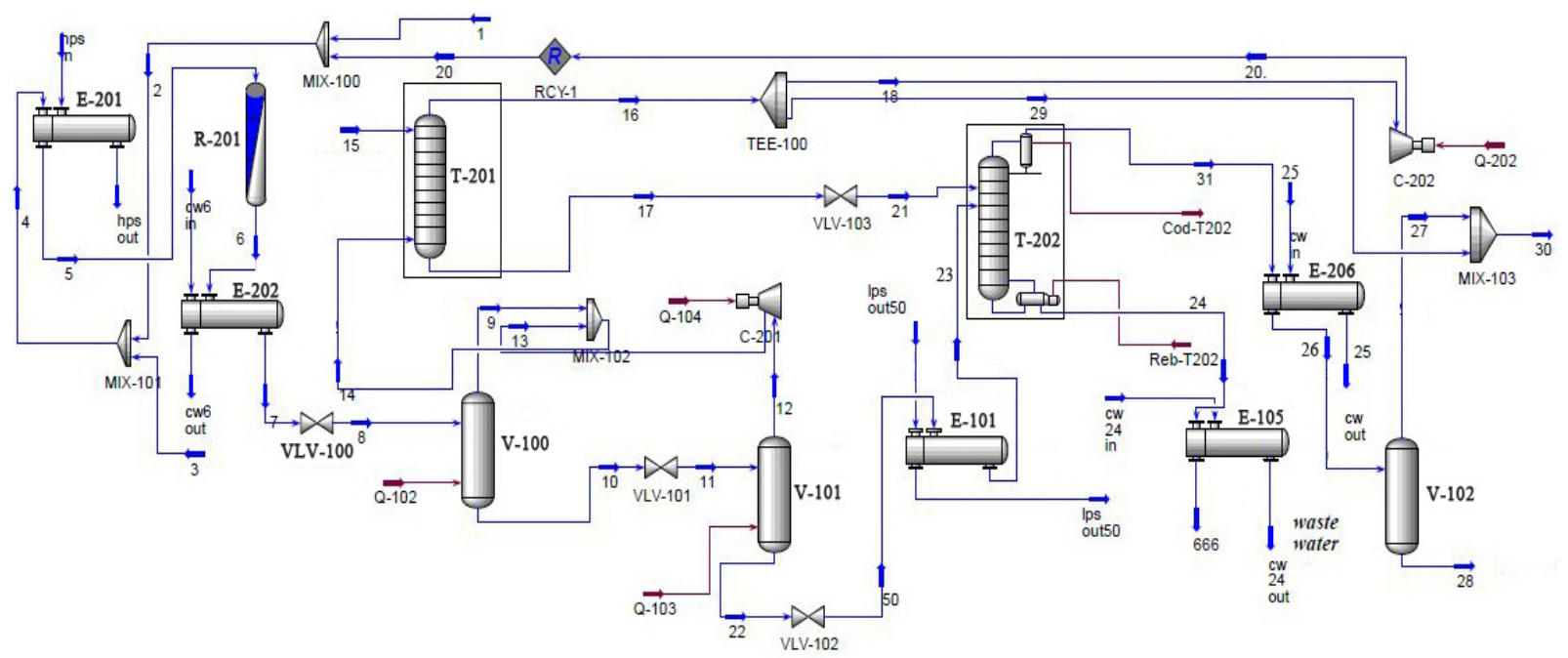

Figure 2. The simulated factory of synthetic ethanol production in HYSYS

According to Figure 2, flow lines 1 and 3, with a temperature of $25^{\circ} \mathrm{C}$, are the flow inlets of the factory. After mixing with the reverse flow of the process (26), they reach the temperature of $85^{\circ} \mathrm{C}$ and the result is flow No. 4 . The flow then enters reactor feed heater. This heat exchanger heats the contents using the steam to prepare the input flow for the reactor reaction conditions that is a temperature of $229^{\circ} \mathrm{C}$ (Sommer \& Bücker, 1983; Millidge 1969; Logsdon, 1994).

The reaction that takes place in reactor R-201 is in equilibrium and incomplete. As a result, majority of initial materials remain inactive in the output of the reactor. The reaction has been experimented over various catalysts. In this article, a mixture of Zirconium and Tungsten is the offered catalyst and it later discusses facilities and investments that should be noted for construction and running of the plant (Reynolds \& Pittwell, 1956; Thomson $\&$ Reynolds, 1952). The considerable reaction (1) occurs in the reactor and $r_{1}$ defines forward reaction and $r_{2}$ implies backward reaction rate.

$$
\begin{aligned}
& \mathrm{C}_{2} \mathrm{H}_{4}+\mathrm{H}_{2} \mathrm{O} \stackrel{\stackrel{r 2}{\stackrel{r}{r}}}{\longleftrightarrow} \mathrm{C}_{2} \mathrm{H}_{5} \mathrm{OH} \\
& r_{2}=\frac{k_{2} P_{A}}{\left(1+K_{W} P_{W}+K_{E} P_{E}+K_{A} P_{A}\right)^{2}} \\
& r_{1}=\frac{k_{1} P_{W} P_{E}}{\left(1+K_{W} P_{W}+K_{E} P_{E}+K_{A} P_{A}\right)^{2}} \\
& K_{1}\left[\mathrm{kmol} \cdot \mathrm{m}^{-3} \cdot \mathrm{cat}^{-1} \cdot \mathrm{h}^{-1} \cdot \mathrm{atm}^{-2}\right]=1.7723 \times 10^{-9} \exp \left(\frac{91130}{R T\left({ }^{\circ} \mathrm{K}\right)}\right) \\
& K_{2}\left[\mathrm{kmol} \cdot \mathrm{m}^{-3} \cdot \mathrm{cat}^{-1} \cdot \mathrm{h}^{-1} \cdot \mathrm{atm}^{-2}\right]=1.3865 \times 10^{-2} \exp \left(\frac{43915}{R T\left({ }^{\circ} \mathrm{K}\right)}\right) \\
& K_{W}\left[\mathrm{~atm}^{-1}\right]=1.2328 \times 10^{-17} \exp \left(\frac{162730}{R T\left({ }^{\circ} \mathrm{K}\right)}\right)
\end{aligned}
$$




$$
K_{E}\left[\mathrm{~atm}^{-1}\right]=2.0850 \times 10^{-4} \exp \left(\frac{35368}{R T\left({ }^{\circ} \mathrm{K}\right)}\right)
$$

Partial pressures are calculated in atmospheric situation. Catalyst void fraction is 0.5 and bulk density is $1.8 \mathrm{gr} / \mathrm{ml}$. Because of using Tungsten-Zirconium catalyst, ethanol will not dehydrate. But the acetylene that is sent to the reactor with ethylene is able to make a reaction with water and produces acetaldehyde too.

$$
\begin{gathered}
\mathrm{C}_{2} \mathrm{H}_{2}+\mathrm{H}_{2} \mathrm{O} \stackrel{r_{3}}{\rightarrow} \mathrm{CH}_{3} \mathrm{CHO} \\
r_{3}=K_{3}\left[\mathrm{kmol} \cdot \mathrm{m}^{-3} \cdot \mathrm{cat}^{-1} \cdot \mathrm{h}^{-1} \cdot \mathrm{atm} \mathrm{tm}^{-2}\right] P_{\text {Acet }}[\mathrm{atm}] \\
K_{3}=1 \times 10^{-4} \exp \left(\frac{-25000}{R T\left({ }^{\circ} \mathrm{K}\right)}\right) \\
\ln K=\frac{-\Delta G^{\circ}}{R T}=\frac{8378}{8.314 \times 298.15}=3.3677
\end{gathered}
$$

Due to chemical kinetics of the reaction and requiring conversion rate, investigation of $\mathrm{K}$ is essential. $\mathrm{K}$ is the constant equilibrium and is computed as the following, assuming it as an ideal gas (Ewell, 1940; Wenner, 1949).

$$
-R T \ln K=\sum \mathcal{V}_{\mathrm{i}} \times \mathrm{G}_{\mathrm{i}}^{\circ} \equiv \Delta \mathrm{G}
$$

The constants relate to fugacity of materials by means of $K=\prod(\widehat{\mathrm{fl}})^{v_{\mathrm{i}}}$ in real equilibrium mixture. This components' fugacity shows real equilibrium of the mixture and they are functions of temperature, pressure and compositions Since gas-phase thermo chemical quantities are more readily found, it is preferable to formulate the chemical equilibrium condition for the vapor phase, as shown (Ravagnani et al., 2010; Schladt et al., 1998):

$$
\left\{\begin{array}{l}
\widehat{f}_{l}=\widehat{\emptyset}_{i} y_{i} P \\
\mathrm{~K}=\Pi\left(\hat{\mathrm{f}}_{\mathrm{i}}\right)^{v_{\mathrm{i}}}
\end{array} \Rightarrow \quad \Pi\left(\widehat{\varnothing}_{\mathrm{i}} \mathrm{y}_{\mathrm{i}}\right)^{\mathrm{v}_{\mathrm{i}}}=\mathrm{P}^{-v_{\mathrm{K}}} \mathrm{K}\right.
$$

Assuming the mixture as ideal, it is concluded that:

$$
\begin{aligned}
& \widehat{\emptyset}_{i}=\emptyset_{i} \quad \Rightarrow \quad \Pi\left(\varnothing_{i} \mathrm{y}_{\mathrm{i}}\right)^{\mathrm{v}_{\mathrm{i}}}=\mathrm{P}^{-v_{\mathrm{V}}} \\
& \frac{y_{E t o h} . \varphi_{E t o h}}{y_{C 2 H 4} . \emptyset_{C 2 H 4} \times y_{H 2 O} . \emptyset_{H 2 O}}=P(0.01568)
\end{aligned}
$$

Thus: $K\left(229^{\circ} \mathrm{C}\right)=0.01568$. Considering the average inlet and outlet reaction temperatures and high pressure conditions in the reactor the fugacity value is approximately $\xi_{\mathrm{e}}=0.2598$.

Regarding the volatility of ethylene, the output flow from the reactor enters the cooling exchanger reactor to gain the proper conditions of being separated from ethylene from product, the output flow enters the low pressure separator from the lower part of reactor feed heater. Flows $9 \& 11$, which are the upper outputs of the separators, are sent to ethanol absorber tower (T-201). To equalize the pressure of the flows 9 and 12, the reciprocating flash gas compressor (C-201) is used.

After mixing, flow No. 14 enters the ethanol absorber column. Owing to the fact that flow 14 contains some ethanol, the water enters the tower T-201 from the upper part through flow No. 15 and absorbs ethanol; the output flow is then sent to purifying column T-202 from the lower portion of the tower.

Flow No. 23 and 21 enter the purifying ethanol purification; the first through the $54^{\text {th }}$ plate and the latter, which is the product of T-201 adsorption column, through the $99^{\text {th }}$ plate. Flow 24 and the lower output of ethanol purification column that encompasses a little ethanol and lots of water will then enter waste water cooler to get cooled through cooling water. 
Table 1. Features of vapour and aqueous phase of production by the plant

\begin{tabular}{lccc}
\hline Stream Name & (28) ethanol & Vapor Phase & Aqueous Phase \\
\hline Vapor / Phase Fraction[Vol Basis] & 0.00 & 0 & 1.00 \\
Temperature[C] & 50.00 & 50.00 & 50.00 \\
Pressure[kPa] & 220.0 & 220.0 & 220.0 \\
Molar Flow [kgmole/h] & 91.78 & 0.00 & 91.78 \\
Mass Flow [kg/h] & 3793 & 0.00 & 3793 \\
Std ideal Liq Vol Flow $\left[\mathrm{m}^{3} / \mathrm{h}\right]$ & 4.695 & 0.00 & 4.695 \\
Molar Enthalpy $[\mathrm{kJ} / \mathrm{kgmole}]$ & $-2.757 \mathrm{e}+005$ & $1.306 \mathrm{e}+004$ & $-2.757 \mathrm{e}+005$ \\
Molar Entropy $[\mathrm{kJ} / \mathrm{kgmole}-\mathrm{C}]$ & 3.113 & 170.5 & 3.113 \\
Heat Flow $\mid \mathrm{kJ} / \mathrm{h}]$ & $-2.530 \mathrm{e}+007$ & 0.00 & $-2.530 \mathrm{e}+007$ \\
Liq Vol Flow @SStd & 4.602 & 0.00 & 4.602 \\
Fluid Package & Basis-2 & $\mathrm{NRTL}$ & \\
\hline
\end{tabular}

Table 2. Component of ethanol produced by the first section of plant

\begin{tabular}{lccc}
\hline Stream & 28 & Vapor phase & Aqueous phase \\
\hline Molecular weight & 41.33 & 29.95 & 41.33 \\
Molar density[kgmole/m3] & 19.16 & $8.305 \mathrm{e}-002$ & 19.16 \\
Mass density[kg/m3] & 791.8 & 2.487 & 791.8 \\
Mass enthalpy[kJ/kg] & -6670 & 436.2 & -6670 \\
Mass entropy[KJ/kg.C] & $7.533 \mathrm{e}-002$ & 5.695 & $7.533 \mathrm{e}-002$ \\
Heat capacity[KJ/kgmole.C] & 143.3 & 49.02 & 143.3 \\
Mass heat capacity [KJ/kg.C] & 3.467 & 1.637 & 3.467 \\
Lower heating value[KJ/kgmole] & $1.027 \mathrm{e}+006$ & $1.284 \mathrm{e}+006$ & $1.027 \mathrm{e}+006$ \\
Mass lower heating value [KJ/kg] & $2.485 \mathrm{e}+004$ & $4.288 \mathrm{e}+004$ & $2.485 \mathrm{e}+004$ \\
Phase fraction [Vol Basis] & $4.941 \mathrm{e}-324$ & 0 & 1 \\
Specific heat[KJ/kgmole.C] & 143.3 & 49.02 & 143.3 \\
Std gas flow [STD_m3/h] & 2170 & 0 & 2170 \\
Std ideal liquid mass density[kg/m3] & 807.8 & 426.7 & 807.8 \\
Z factor & - & 0.9859 & $4.274 \mathrm{e}-003$ \\
Watson K & 10.76 & 16.40 & 10.76 \\
\hline
\end{tabular}

\section{Optimizing Process to 99.7 Percent Purity}

The design of effective processes for environmental friendly fuels by means of additive ethanol implies implementation of the best procedure and definition of a suitable process. Configurations that make the production possible until the final product meets given characteristics must be specified. The task of defining a proper configuration of the process requires the assessment of many process simulators for finding the modifying process with improved and organized performance indicators.

Using ASPEN PLUS in a synthesis process can significantly enhance process condition predictions and products. This simulator allows optimization for attaining a raw ethanol with $99.7 \%$ purity produced in the earlier explained section. Much has been done about azeotrope fracturing in water-ethanol solutions so far; the prominent parts of studies however have been focused on purifying through extraction (Gerbaud et al., 2006; Langston et al., 2005). Until recently, benzene was the most important material for purifying studies due to its features of destroying azeotrope. However, the produced ethanol via this method was perilous enough to create quite irreplaceable damages. 
Ethanol purification column has a partial type of condenser and separation of steam from liquid is done via reflux drum. The liquid outlet is then pumped back to the tower through P-201 A/B reflux pumps and the steam outlet from reflux drum that contains huge amounts of the product is sent to E-206 product condenser to get cooled by cooling water; transforming vapor of ethanol to liquid state is the reason of this stage.

Noting that ethanol is sold in liquid state, the negligible amounts of ethylene vapor from the upper portion of V-204 are sent to the flare to be burnt. The product's flow line contains 87 mole percentage of ethanol. Figure 3 demonstrates the additional attached unit to the main one that improves the purity of the final product from $87 \%$ to $99.7 \%$.

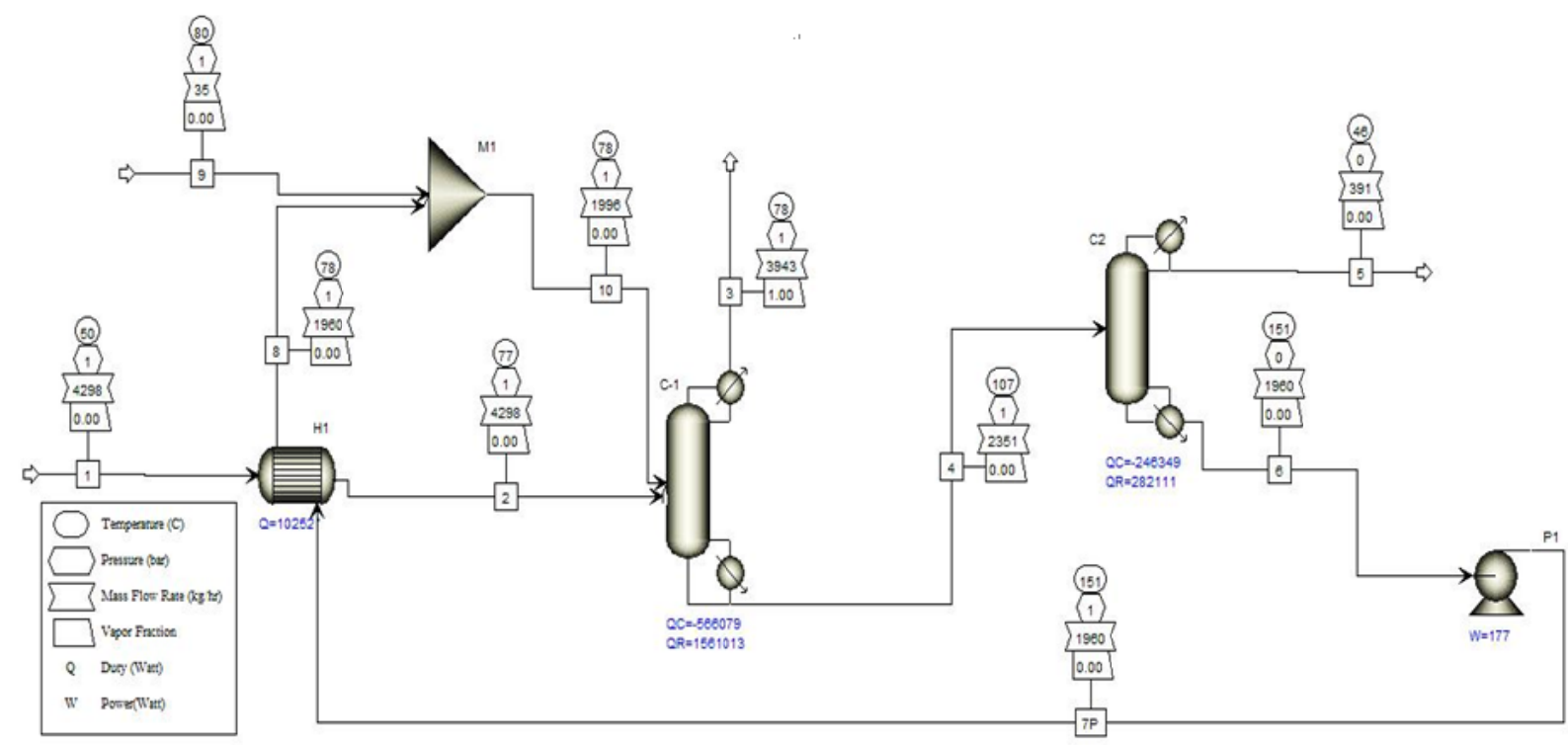

Figure 3. The additional attached process unit to the main plant

Nowadays, studies are being conducted to be rid of azeotrope using ethylene glycol and salt as separators for fracturing azeotrope and convincing results were concluded. The product of the new method does not have the previous problems for the consumers (Ravagnani et al., 2010; Schladt et al., 1998). Most of the ethanol process industries are still using the extractive distillation to obtain anhydrous ethanol (Ravagnani et al., 2010). Extractive distillation is done to achieve pure ethanol using ethylene-glycol and tetra ethylene-glycol as solvents.

Simulation results for the produced ethanol/water mixture are illustrated in the rest of the paper. The output of the optimized system in flow No. 3 is 99.7 percent which is the main reason of the produced ethanol being sold by more prices in the global market. Azeotrope is formed at a minimum-boiling with water at 90 mol percentage while the pressure of column which is considered atmospheric.

This azeotrope must be broken to result anhydrous ethanol (Ethanol News Magazine, 2009). The equilibrium graph in Figure 5 shows the azeotrope fracture after using Calcium Chloride and ethylene glycol. The plant used for this process result is illustrated in Figure 3 in which the entire process indices can be reviewed. In addition, the amount of work and heating of the equipments are specified. Optimizing method is designed so that the output flow of the company is transferred to the separation unit to isolate ethanol from water. Dehydration is done using salt and ethylene glycol and the method is known as extractive distillation. The output flow of the first process is unified with the conditions of flow No. 1 in the separation unit, i.e. a pressure of one atmosphere. With a few changes, the purity can reach $89 \%$ from $87 \%$ which is not a subject to be discussed in this article.

Firstly, flow No. 1 of the separation unit enters a preheater for its temperature to be increased from $50^{\circ}$ to $78{ }^{\circ} \mathrm{C}$. This action is done to improve the operational conditions for entering the hydration column $\mathrm{C} 1$, decrease the thermal load of the reboiler, and retrieve energy of this flow. The heating is done through the recursive process flow (7).

The temperature of flow No. 7 then decreases from $150^{\circ} \mathrm{C}$ to $80^{\circ} \mathrm{C}$. Afterward in $\mathrm{M} 1$ flow 8 is mixed with flow 9 that contains salt and ethylene glycol. Flow No. 10, unlike flow No. 2, enters from the upper part of the tower into the first tray and the feeding line enters from the $12^{\text {th }}$ tray. In hydration column, isolation of ethanol from 
water is done and in the upper part of the column, flow No. 3, containing ethanol with $99.7 \%$ purity is gained. Flow No. 4, the output from the lower part of hydration column, consists of ethylene glycol and water; it enters recovery column $\mathrm{C} 2$ to have water separated from ethylene glycol and salt and retrieve the solvent.

Table 3. Outlet data of optimized products in Aspen Plus

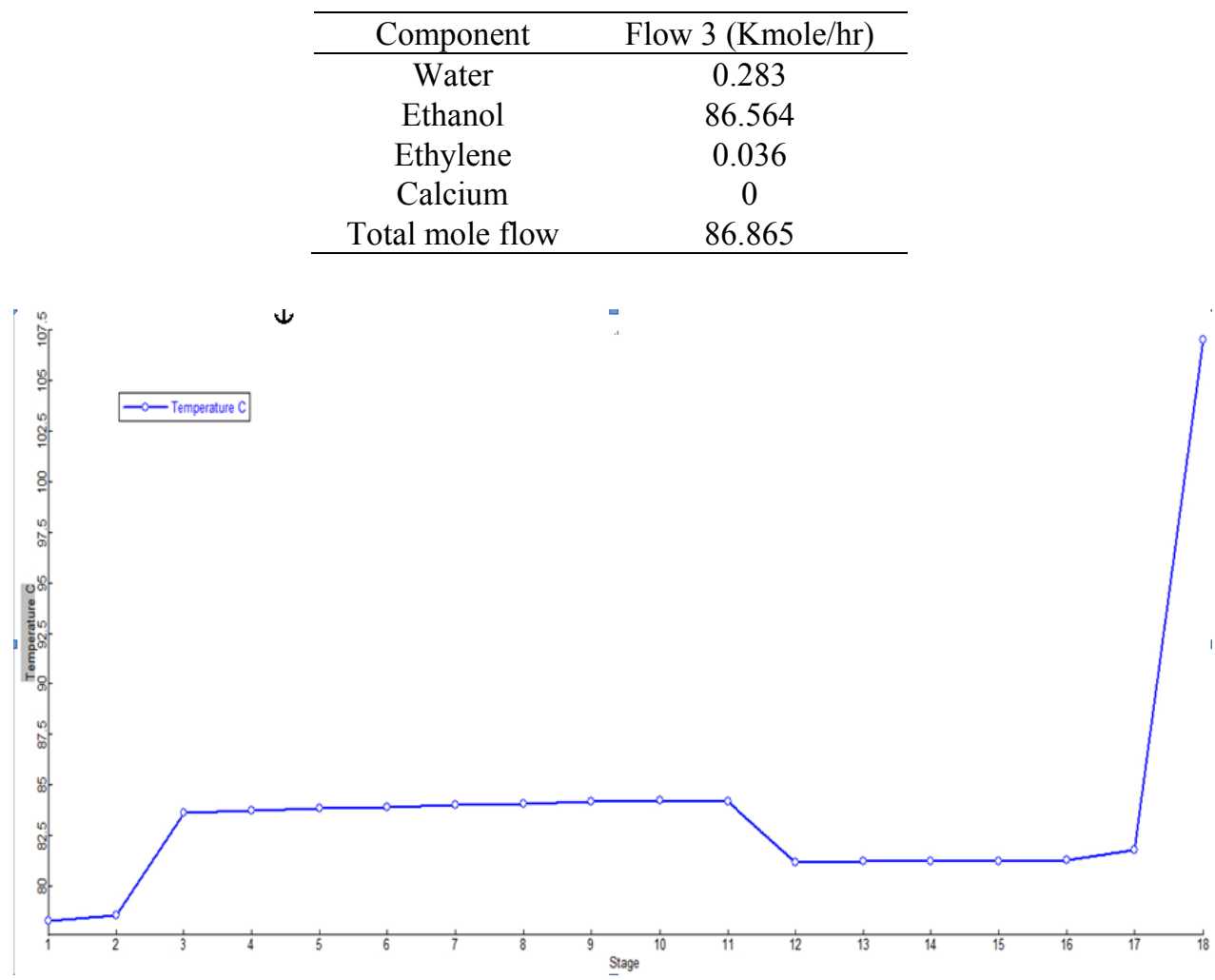

Figure 4. Temperature treatment versus each stage in hydration column

The flow (5) above the column is filled with water and the lower flow (6) contains ethylene glycol and salt. The maximum temperature in the reboiler of recovery column is $150^{\circ} \mathrm{C}$; since ethylene glycol is majorly decomposed Flow No. 6 gains the necessary pressure using pump B1 and flow No. 7 is retrieved and sent back to the process. The final purity of ethanol in both liquid and vapor phase is demonstrated in Figure 5.

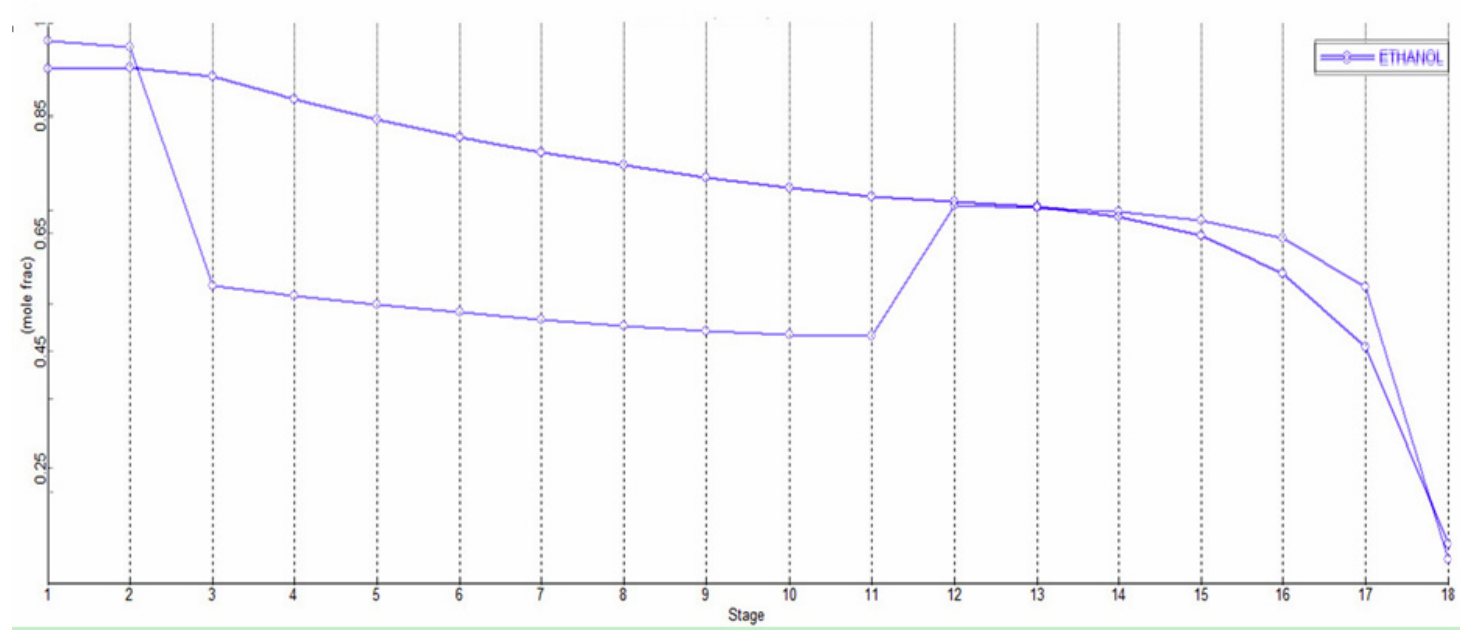

Figure 5. Ethanol vapor and liquid composition treatment versus each stage in hydration column 


\section{Conclusion}

According to the modeled process, ethanol is produced with $99.7 \%$ purity. Noting the fact that global environmentalist and scientists believe that ethanol is needed in massive amounts in the near future, the areas in which there is the potentiality of ethanol production should be examined. Increased costs of agricultural products and their shortage in Iran and therefore the inability of producing ethanol through fermenting method proves the idea that direct hydration is the best accessible method for mass production of ethanol that is economical referring to the available sources in the country. Besides, regarding the optimization and purity improvement of the produced ethanol in this study, an increased value of the product would be reached due to its high purity. Noting the necessity of synthetic ethanol production and the economic justification of the issue, stable conditions would be held for internal production of ethanol in the country and later for massive exports.

\section{References}

Bristow, M. (2009). Chemical Industry News \& Intelligence (ICIS.com). INEOS restartssynthetic ethanol unit at Grangemouth, ICIS News (June 5).

Carlos, A., \& Cardona Oscar, S. (2007). Fuel ethanol production: Process design trends and integration opportunities. Bioresource Technology, 98, 2415-2457. http://dx.doi.org/10.1016/j.biortech.2007.01.002

Chemical Industry News \& Intelligence (ICIS.com). (1998). Peak practice, ICIS News (March 16).

Chemical Industry News \& Intelligence (ICIS.com). (2005). Industrialethanol market tightening, ICIS News.

Devon, R., \& Schwartz, M. L. (1972). Chem. Eng., 79(19), 50-51.

Ethanol Industry News. (2011). Daily breaking news on world sugar and ethanol market industry. Retrieved from www.sugarind.com/2011/08/world-top-20-ethanol-producing

Ethanol News Magazine. (2009). Ethanol Council of Iran, 23, 11.

Ethanol News Magazine. (2010). Ethanol Council of Iran, 35(27), 12-14.

Ewell, R. H. (1940). Calculation of Chemical Equilibrium at High Pressures. Ind. Eng. Chem., 32, 147-153. Chem. Abs., 34, 3158.

Gerbaud, V., Joulia, X., Rodriguez-Donis, I., Baudouin, O., Rosemain, O., Vacher, A., \& Castelain, P. (2006). Practical residue curve map analysis applied to solvent recovery in non-ideal binary mixtures by batch distillation processes. Chemical Engineering and Processing, 45, 672-683. http://dx.doi.org/10.1016/j.cep.2005.11.011

Gilmartin, G. (2005). Chemical Industry News \& Intelligence (ICIS.com). Sasol's Herne ethanol plant back onstream, ICIS News (September 15,). Retrieved from http://www.icis.com

Griswold, J., Haney, J. D., Klein, V. A. (1943). Ethanol-Water System. Vapor-Liquid Properties at High Pressures. Ind. Eng. Chem., 35, 701. http://dx.doi.org/10.1021/ie50402a015

Langston, P., Hilal, N., Shingfield, S., \& Webb, S. (2005). Simulation and optimisation of extractive distillation with water as solvent. Chemical Engineering and Processing, 44, 345-351. http://dx.doi.org/10.1016/j.cep.2004.05.008

Logsdon, J. E. (1994). Ethanol In: J. I. Kroschwitz and M. Howe-Grant (Eds.) Kirk-Othmer Encyclopedia of Chemical Technology (4th ed.). New York: John Wiley \& Sons

Maki, Y., Sato, K., Isobe, A., Iwasa, N., Fujita, S., Shimokawabe, M., \& Takezawa, N. (1998). Structures of $\mathrm{H} 3 \mathrm{PO} 4 / \mathrm{SiO} 2$ catalysts and catalytic performance in the hydration of ethene. Appl Catal A: General, 170(2), 269-275. http://dx.doi.org/10.1016/S0926-860X(98)00054-4

National Petrochemical Company. (2005). NPC News Bulletein, 67, 23-27.

Nelson, C. R., Taylor, M. A. D., Davidson, D. D., \& Peters. (1951). L.M. US Patent 2,579,601 for Shell Development Co.

Ravagnani, M. A. S. S., Reis, M. H. M., MacielFilho, R., \& Wolf-Maciel, M. R. (2010). Anhydrous ethanol production by extractive distillation: a solvent case study. Process Safety and Environmental Protection, 88, 67-73. http://dx.doi.org/10.1016/j.psep.2009.11.005

Renewable Fuels Association. (2012). Accelerating Industry Innovation. 2012 Ethanol Industry Outlook, Renewable Fuels Association

Reynolds, P. W., \& Pittwell, L. R. (1956). Hydration of Olefins With Tungsten ,US Patent (2755309). 
SADAF, Saudi Petrochemical Co. (2010). In Focus, the SADAF Team: The Right Chemistry in a Tough Global Arena. Retrieved from http://www.barrowandschuck.com/pdf/

Schladt, L., Ivens, I., Karbe, E., Ruhl-Fehlert, C., \& Bomhard, E. (1998). Sub acute oral toxicity of tetraethylene-glycol and ethylene-glycol administered.

Thomson, R. C., \& Reynolds, P. W. (1952). Assigned to Imperial Chemical Industries Ltd. British Patent 665, 214.

Wenner, R. R. (1949). Prediction of Reaction Equilibria. Chem. Eng. Progress, 45, 194-207. 